Check for updates

Cite this: RSC Adv., 2019, 9, 37222

Received 11th September 2019 Accepted 14th October 2019

DOI: 10.1039/c9ra07301a

rsc.li/rsc-advances

\section{Unusual adsorption behaviours and responsive structural dynamics via selective gate effects of an hourglass porous metal-organic framework $\dagger$}

\author{
Ying Xiong, (D) ab Yan-Zhong Fan, ${ }^{a}$ Zhang-Wen Wei, ${ }^{a}$ Cheng-Xia Chen, ${ }^{a}$ Sha Chen, ${ }^{a}$ \\ Dawei Wang, (iD a Mihail Barboiu, (ID ac Ji-Jun Jiang (iD *a and Cheng-Yong Su (D) ad
}

\begin{abstract}
An hourglass porous metal-organic framework, LIFM-12, constructed on a T-shaped flexible ligand with $\mathrm{Cu}^{2+}$ paddle-wheel clusters, shows temperature and gas adsorption responsive structural dynamics upon reversible molecular guest binding. Temperature-dependent single crystal and powder $\mathrm{X}$-ray diffraction experiments show that the open gate status of the framework with adaptive behaviours facilitates kinetic diffusion of gas molecules resulting in the sequential filling of pores of different sizes, thus creating a breathing behaviour reminiscent of the observation of several steps in adsorption isotherms. In addition, adsorption studies revealed that LIFM-12 performs exceptional adsorption selectivity of 10-25 for $\mathrm{CO}_{2}$ versus light gases $\mathrm{N}_{2}, \mathrm{CH}_{4}$, and $\mathrm{CO}$ and up to 200 for $\mathrm{C}_{3} \mathrm{H}_{6}$ versus $\mathrm{CH}_{4}$.
\end{abstract}

\section{Introduction}

Metal-organic frameworks (MOFs) is a hot research topic in the past decades and attracts intense interest in the investigation of their fascinating structures and potential applications such as separation, ${ }^{1-4}$ gas storage,$^{5-8}$ and catalysis. ${ }^{9-13}$ Many efforts focus on structural design, surface modification and functional tuning of the rigid coordination frameworks. On the other hand, it has been found that some unique properties, like extraordinary gas adsorption/separation behaviors, can be obtained via internal structural dynamics. For example, gateopening $^{\mathbf{1 4 - 1 6}}$ and breathing ${ }^{\mathbf{1 7 - 2 0}}$ behaviors are important known phenomena, occurring through reversible structural transitions between two or more states triggered via pressure or temperature variations or guest binding, providing a unique approach to develop multifunctional porous materials. ${ }^{21,22}$

The dynamic behaviors of MOFs in response to external stimuli, can be triggered by several mechanisms, such as sliding of interlocked fragments of interpenetrated frameworks, ${ }^{\mathbf{2 3 , 2 4}}$

\footnotetext{
${ }^{a}$ MOE Laboratory of Bioinorganic and Synthetic Chemistry, Lehn Institute of Functional Materials, School of Chemistry, Sun Yat-Sen University, Guangzhou 510275, P. R. China. E-mail: jiangjij@mail.sysu.edu.cn

${ }^{b}$ Life Science Institute, Jinzhou Medical University, Jinzhou 121001, P. R. China ${ }^{c}$ Adaptive Supramolecular Nanosystems Group, Institut Européen, des Membranes, Place Eugène Bataillon, CC047 34095 Montpellier Cedex 5, France

${ }^{d}$ State Key Laboratory of Applied Organic Chemistry Lanzhou University, Lanzhou 730000, P. R. China

$\dagger$ Electronic supplementary information (ESI) available: Additional information including PXRD patterns, X-ray single crystal diffraction data, gas adsorption-desorption isotherms, TG/DTG curves and tables. CCDC 1865055-1865058. For ESI and crystallographic data in CIF or other electronic format see DOI: 10.1039/c9ra07301a
}

coordination geometry rearrangements of metal centers or clusters, ${ }^{25-27}$ rotational motion involving flexible parts of bridging ligands, ${ }^{\mathbf{1 6}, \mathbf{2 8 - 3 3}}$ or a combined mechanism containing more than one of the above three. Since interpenetration often leads to a shrink of solvent accessible volume, ${ }^{34-36}$ we pay more attention to the geometry rearrangement of the coordination environment and to the bond rotation of organic linkers. ${ }^{20,37-41}$ If the framework flexibility and dynamics are generated by the bond rotation, it usually neither changes the topology of the whole framework nor dramatically reduces porosity. Moreover, it can temporarily open the narrow apertures of the coordination framework to facilitate kinetic diffusion of guest molecules and/or accept oversized guest molecules to give stepwise sorption behavior, ${ }^{\mathbf{4 2 - 4 4}}$ thus providing specific applications for gas separation, bio-chemical sensing, etc. Although the dynamic behaviors have been discovered in lots of MOFs and fruitful research has been conducted, the detailed interpretation of the mechanisms of such behaviors, especially from the aspects of crystalline structures by X-ray single crystal diffraction, is still rare, ${ }^{4,46}$ partly because MOFs may easily lose its crystalline when they are under heating (or cooling) and/or guest inclusion (or exclusion) process. In addition, comprehensive studies upon the temperature and guest effects on the dynamic structures are also highly required.

In this paper, we report an hourglass porous MOF constructed from a T-shaped flexible ligand and $\mathrm{Cu}^{2+}$ paddle-wheel clusters, behaving variable gate effects, structural dynamics and excellent framework robustness induced by covalent bond rotation (Scheme 1) in response to temperature and gas inclusion/release, without loss of the single crystallinity. Experimental single-crystal X-ray diffraction, X-ray powder diffraction (PXRD), gas adsorption and theoretical simulations 

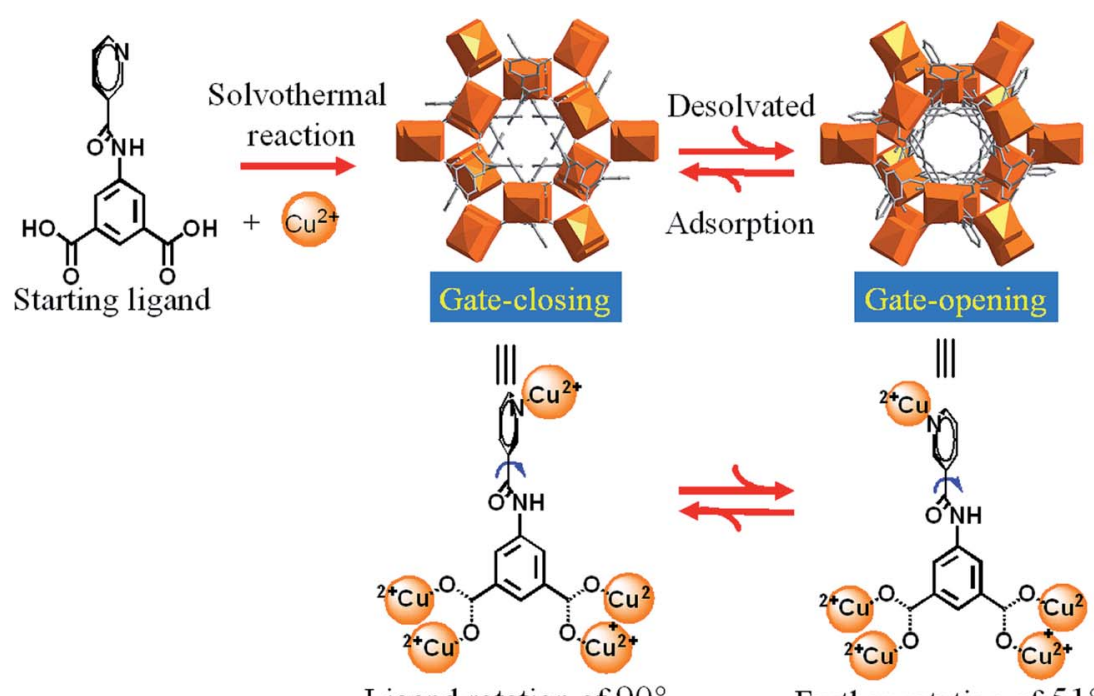

Ligand rotation of $90^{\circ}$

Further rotation of $51^{\circ}$

Scheme 1 Gate opening/closing via guest removal and inclusion processes, controlled by the dynamic rotation of pyridyl ring and amide group of $\mathrm{H}_{2} \mathrm{NIA}$ ligand.

have been combined to elucidate the detailed structural dynamics for the stepwise adsorption isotherms, disclosing exceptional adsorption selectivity of $10-25$ for $\mathrm{CO}_{2}$ versus light gases $\mathrm{N}_{2}, \mathrm{CH}_{4}$ and $\mathrm{CO}$ and up to 200 for $\mathrm{C}_{3} \mathrm{H}_{6}$ versus $\mathrm{CH}_{4}$ hydrocarbons.

\section{Results and discussion}

\section{Solid crystal structure of LIFM-12}

Solvothermal reactions of $\mathrm{Cu}^{2+}$ with similar T-shaped ligands 4pyridylaminocarbonyl $\left(\mathrm{H}_{2} \mathrm{INIA}\right)$ and 1-oxidopyridin-1-ium-4ylamino carbonyl ( $\mathrm{H}_{2}$ INOIA) afforded two rtl topological $\mathrm{Cu}-$ MOFs, LIFM-10(Cu), LIFM-11(Cu) through a ligand-to-axial pillaring strategy. ${ }^{47-49} \mathrm{MOF}$ of $\left[\mathrm{Cu}\left(\mathrm{C}_{14} \mathrm{~N}_{2} \mathrm{O}_{5} \mathrm{H}_{8}\right)\right] \cdot 1.33 \mathrm{DMF} \cdot 2 \mathrm{H}_{2}-$ $\mathrm{O}$ (LIFM-12) was constructed through a similar strategy with the modified ligand $\mathrm{H}_{2}$ NIA (Table $\mathrm{S} 1 \dagger$ ). The T-shaped ligand, 5(nicotinoylamino)isophthalic acid $\left(\mathrm{H}_{2} \mathrm{NIA}\right)$, prepared for the studies described here, contains two carboxylates and a pyridine coordinating sites, as well as an amido group that can potentially bind the guests and serves as a rotating engine under external stimulus (Scheme 1). Single crystals of LIFM-12 were obtained by solvothermal conditions.

The backbone is composed of paddle wheel binuclear $\mathrm{Cu}_{2}-$ units, bridged by the organic linker NIA ${ }^{2-}$ (Fig. 1a) to generate 3D microporous architecture (Selected bond length and angles are listed in Table $\mathrm{S} 2 \dagger$ ). A one-dimensional (1D) hourglass channel is formed two cavities of different sizes alternately aligned along $c$-axis: the small Cavity A is about $10 \AA$ in diameter and looks like a Chinese drum (Fig. 1b), while the larger Cavity B is about $12 \AA$ in diameter and shows turbinate shape (Fig. 1c). The cavities A and B are connected through a narrow neck constituted of three pyridyl rings (Fig. 1b). Therefore, although LIFM-12 exhibits the same rtl topology ${ }^{50-52}$ (Fig. 1e and S1†) as LIFM-10(Cu), the porous nature is completely different. When comparing two structures, we can find that the ligand INIA ${ }^{2-}$ in LIFM-10(Cu) is co-planar but displays a slight bending shape to satisfy the connection requirement of rtl topology (Fig. S2a †), suffering some framework stress to hinder the amide group from rotation. While in LIFM-12, the pyridyl ring and amide group of NIA $^{2-}$ rotate from the basic benzene plane to coordinate with $\mathrm{Cu}^{2+}$, fulfilling the requirement of rtl topology without bending stress (Fig. S2b†). The rotation of the pyridyl groups inward to the pores leads to a narrow junction between cavities $\mathrm{A}$ and $\mathrm{B}$, thus controlling the gas diffusion along the $1 \mathrm{D}$ hourglass channel (vide infra). PLATON calculation indicates that potential solvent accessible void of LIFM-12 framework is $51.4 \%$ (all solvent molecules are ignored to calculate the potential solvent accessible void, sic passim). ${ }^{53}$

\section{Stability of LIFM-12}

Thermal gravimetric analysis (TGA) shows that the framework of LIFM-12 is stable upon heating up to $531 \mathrm{~K}$ under $\mathrm{N}_{2}$. The weight-loss ratio before $531 \mathrm{~K}$ is $21.5 \%$, corresponding to 1.33 DMF and 2 water molecules for each asymmetric unit (Fig. S4†). The phase purity for LIFM-12 is identified by PXRD (Fig. S5†). Bulk samples are stable in air for half a year and maintain the porous structure after being desolvated at $433 \mathrm{~K}$ under a dynamic vacuum at $10^{-3}$ torr for 20 hours (Fig. S6†). It is not stable after immersing in water after a week (Fig. S7 $\dagger$ ). Interestingly, LIFM-12 is stable in a selected solvent like methanol, chloroform, and tetrahydrofuran at room temperature (Fig. S8 $\dagger$ ). Temperature-dependent PXRD measurements have been carried out under the $\mathrm{N}_{2}$ atmosphere for LIFM-12. As shown in Fig. 2 and S9, $\dagger$ the framework can persist its backbone around $523 \mathrm{~K}$ after removal of the solvent in the lattice. Peaks shifted a little at $2 \theta=7.4^{\circ}$ and between $10.9-12.3^{\circ}$ and $14.2-$ $15.7^{\circ}$ which should be attributed to slight readjustment during the heating process. 


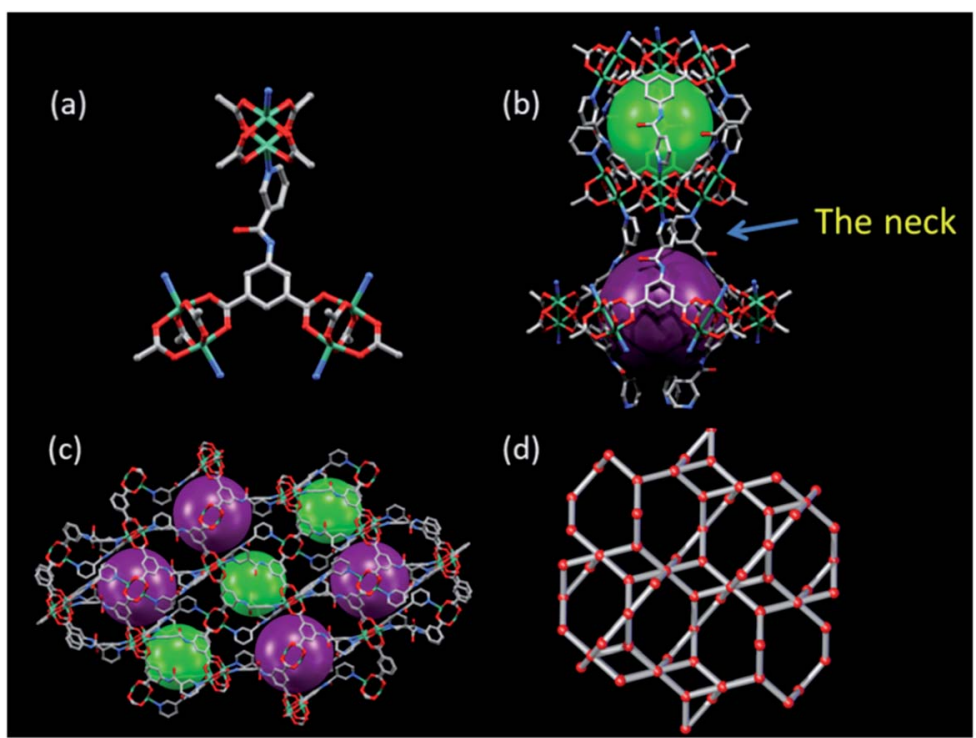

Fig. 1 (a) The ligand $\mathrm{NIA}^{2-}$ and the $\mathrm{Cu}^{2+}$ paddle wheel units of LIFM-12, (b) cavities A and B, connected via a narrow neck within the structure of MOF (c) crystal packing and (d) topological representations of the porous framework of LIFM-12.

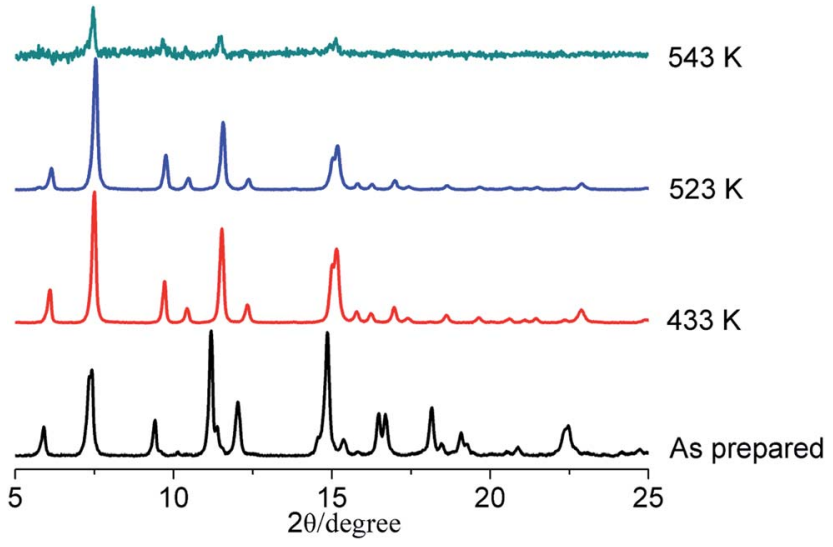

Fig. 2 Temperature-dependent PXRD patterns of LIFM-12.

\section{Structural dynamics upon heating}

Temperature-dependent PXRD of LIFM-12 analysis showed a robust framework upon heating at high temperature and then cooling under air and $\mathrm{N}_{2}$. Three new X-ray single crystal structures of LIFM-12-HT (heated at $435 \mathrm{~K}$ under $\mathrm{N}_{2}$ ), LIFM-12LT (heated at $435 \mathrm{~K}$ then cooling down to room temperature under $\mathrm{N}_{2}$ ) and LIFM-12- $\mathbf{H}_{2} \mathrm{O}$ (heated at $435 \mathrm{~K}$ then cooling down under air to room temperature) were afforded in this in situ process. LIFM-12-HT showed a decline of the cell volume of $4.3 \%$ and a slight shortening of three axes of cell parameters. The potential solvent accessible voids reduced from $51.4 \%$ to $45.7 \%$ as calculated by Platon. ${ }^{54}$ No guest molecules are observed in the apertures. The desolvated framework reveals that the amide group and terminal pyridyl rings rotate slightly after removal of guest molecules outside the channels, the rotational angle of the amide groups is $50.8^{\circ}$ (Fig. S10†). The most striking difference is that the neck between cavities A and B turns open by the rotation of amide and pyridine groups (Scheme 2). This state was named as open pore model (OPM). Crystal volume and potential solvent accessible voids of LIFM12-LT remain almost the same, giving unchanged chemical content (Table S3†). LIFM-12-LT can reabsorb water molecules when exposed to air.

Then following water re-adsorption, the hydrated framework is similar with LIFM-12 while the amide and pyridine groups

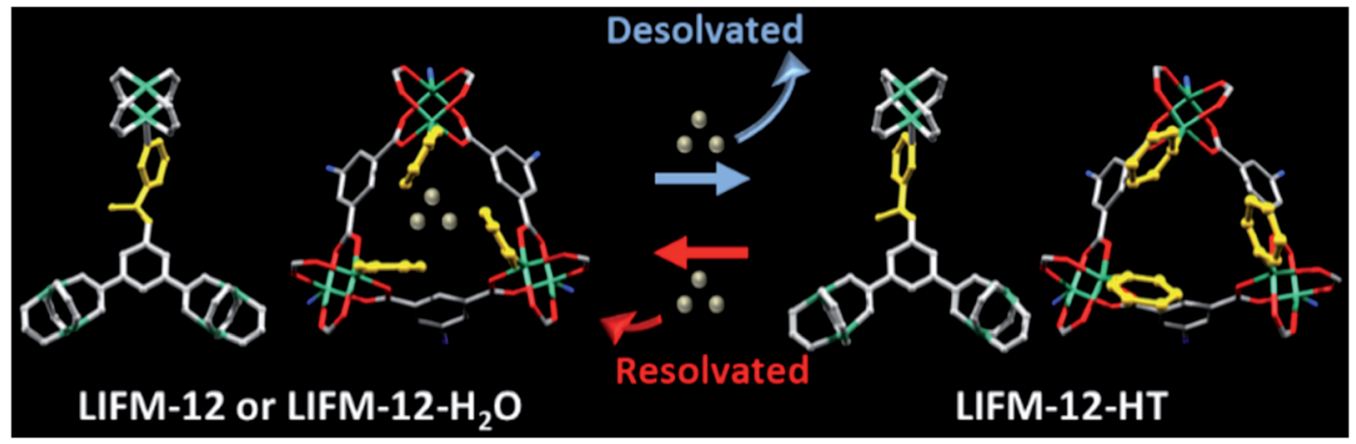

Scheme 2 Desolvation/resolvation processes of LIFM-12. Water molecules in LIFM-12 or LIFM-12- $\mathrm{H}_{2} \mathrm{O}$ are represented by silver balls. 
Table 1 The regions of steps for each gas at $77 \mathrm{~K}$

\begin{tabular}{|c|c|c|c|c|}
\hline & $\begin{array}{l}\text { The region of } \\
\text { the first step }\left(P / P_{0}\right)\end{array}$ & $\begin{array}{l}\text { The region of the } \\
\text { second step }\left(P / P_{0}\right)\end{array}$ & $\begin{array}{l}\text { The region of } \\
\text { the third step }\left(P / P_{0}\right)\end{array}$ & Hysteresis \\
\hline $\mathrm{CO}$ & $\sim 0.02$ & $0.02-$ & - & 0 \\
\hline $\mathrm{O}_{2}$ & $\sim 0.05$ & $0.05-0.10$ & $0.1-$ & 0 \\
\hline $\mathrm{N}_{2}$ & $\sim 0.007$ & $0.007-0.06$ & $0.06-$ & 0 \\
\hline
\end{tabular}

(a)

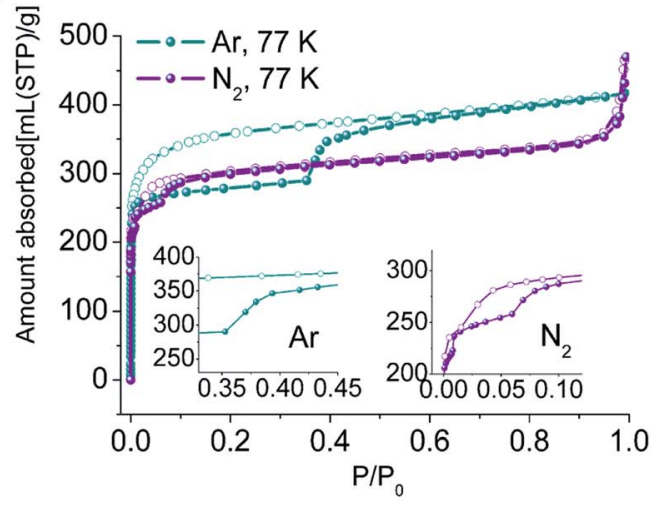

(b)

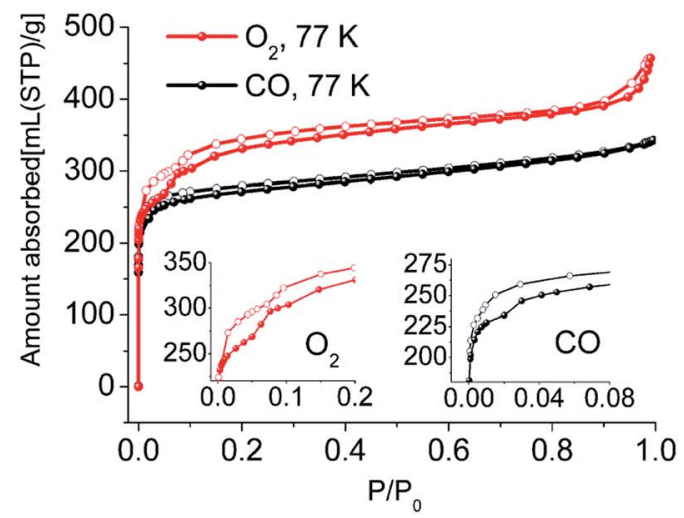

Fig. 3 Gas sorption isotherms of $\mathrm{N}_{2}, \operatorname{Ar}(a) \mathrm{O}_{2}, \mathrm{CO}$ (b) measured at $77 \mathrm{~K}$. Solid symbols: adsorption, open symbols: desorption. Inset: curves of partial enlargement of corresponding sorption isotherms (Saturation pressure at $77 \mathrm{~K}$ of $\mathrm{Ar}$ : 210 torr; $\mathrm{N}_{2}: 760$ torr; $\mathrm{O}_{2}: 156$ torr; $\mathrm{Ar}$ : 453 torr).

switch back to partly shield the neck between cavities A and B. The potential solvent accessible void slightly expands from $46.1 \%$ to $52.7 \%$ and is similar with the void of primitive LIFM12 (Fig. S11†). This new structure form was named as closed pore model (CPM). The above results conclude that the framework of LIFM-12 is overall robust but the organic ligands exhibit mobility upon heating/cooling, which is in agreement with the peak shift at $2 \theta=7.4^{\circ}$ and between $10.9-12.3^{\circ}$ and $14.2-15.7^{\circ}$ of VT-PXRD patterns (Fig. S12†).

\section{Gas adsorption and selectivity}

The $\mathrm{N}_{2}, \mathrm{O}_{2}, \mathrm{CO}$, Ar adsorption isotherms of activated sample LIFM-12 were performed at $77 \mathrm{~K}$. The $\mathrm{N}_{2}$ sorption isotherms display similar Type-I sorption behavior. Interestingly, the adsorption branch of isotherms exhibits three distinct steps in the relative pressure range of $10^{-7} \sim 0.007,0.007-0.06$ and $0.06-$ 0.90. The BET surface area calculated in the range of $P / P_{0}=$ $0.069-0.089$ is $1221.1 \mathrm{~m}^{2} \mathrm{~g}^{-1}$, the pore volume is estimated to be $0.51 \mathrm{~cm}^{3} \mathrm{~g}^{-1}$ at $P / P_{0}$ of 0.90 (Table S4 $\dagger$ ). The $\mathrm{O}_{2}$ adsorption (a)

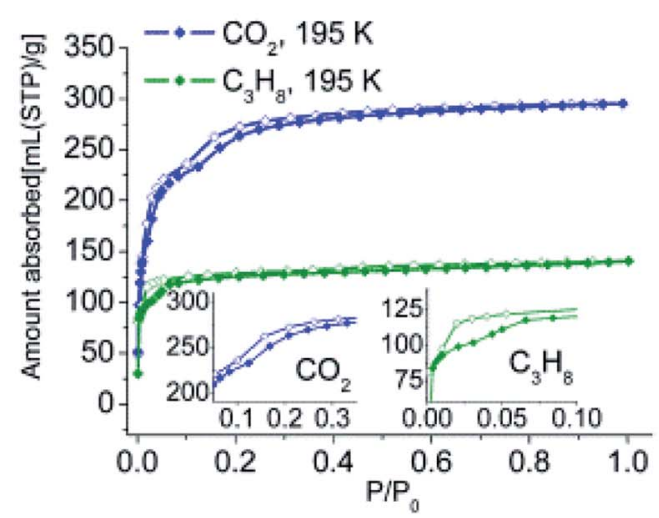

(b)

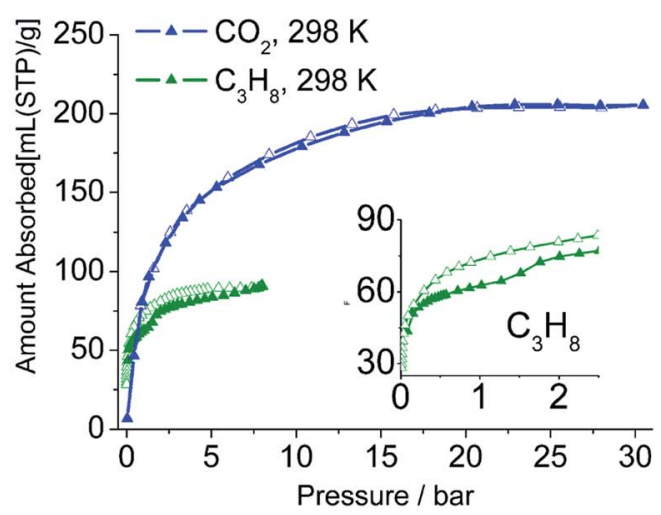

Fig. 4 Gas sorption isotherms of $\mathrm{CO}_{2}, \mathrm{C}_{3} \mathrm{H}_{8}$ measured at $195 \mathrm{~K}(\mathrm{a})$ and $298 \mathrm{~K}$ (b) solid symbols: adsorption, open symbols: desorption. Inset: curves of partial enlargement of corresponding sorption isotherms at high pressure and $298 \mathrm{~K}$. 
isotherms exhibit three distinct steps ending at $P / P_{0}=0.05,0.1$ and 0.3, respectively. The adsorption isotherms of $\mathrm{CO}$ and $\mathrm{Ar}$ at $77 \mathrm{~K}$ present two steps, with the second step beginning at $P / P_{0}=$ 0.02 for $\mathrm{CO}$ and at 0.35 for Ar (Table 1). Interestingly, large hysteresis that closes to the adsorption branches at very low pressure in each isotherm were observed. They can be attributed to the trapping effect of the gas in the pores ${ }^{53}$ caused by the disadvantaged diffusion at a rather low temperature (Fig. 3).

As viewed in Fig. 4, both the $\mathrm{CO}_{2}$ and $\mathrm{C}_{3} \mathrm{H}_{8}$ adsorption isotherms at $195 \mathrm{~K}$ show two distinct steps, and the desorption branch of $\mathrm{C}_{3} \mathrm{H}_{8}$ shows clear hysteresis. $\mathrm{CO}_{2}$ adsorption at $298 \mathrm{~K}$ and 30 bar indicates none of the steps. The $\mathrm{C}_{3} \mathrm{H}_{8}$ adsorption isotherm at $298 \mathrm{~K}$ exhibits stepwise behaviors and hysteresis. The vapor adsorption isotherms of methanol, ethanol, and propanol all exhibit two-step stepwise behavior. The total adsorption amount decreases as critical molecular size increases following the sequence of $\mathrm{MeOH}>\mathrm{EtOH}>n-\mathrm{PrOH}$ (Fig. S13†).

Low pressure $\mathrm{CO}_{2}$ adsorption analysis at $273 \mathrm{~K}, 298 \mathrm{~K}$ and 308 $\mathrm{K}$ achieved 125.6, 87.0, $56.1 \mathrm{ml} \mathrm{g}^{-1}$ (5.6, 3.9, $2.5 \mathrm{mmol}$ ), which belongs to commendable values among MOFs (Fig. S14 and Table S5 $\dagger$ ). The coverage-dependent adsorption isosteric heat (calculated based on the virial method ${ }^{55-57}$ ) lies in a range of 31.2$28.8 \mathrm{~kJ} \mathrm{~mol}^{-1}$ (Fig. S15†). Comparison with MOFs without UMCs (Unsaturated Metal Centers) shows that LIFM-12 possesses lower adsorption heat than that in CuBTTri-mmen $\left(96 \mathrm{~kJ} \mathrm{~mol}^{-1}\right),{ }^{58}$ BioMOF-11 (47 kJ mol $\left.{ }^{-1}\right)^{59}$ and $\left\{[\mathrm{CuL}] \cdot \mathrm{DMF} \cdot 2 \mathrm{H}_{2} \mathrm{O}\right\}_{n}\left(46 \mathrm{~kJ} \mathrm{~mol}^{-1}\right)^{60}$ and slightly surpasses $\mathrm{Cu}(\mathrm{bpy}-1)_{2}\left(\mathrm{SiF}_{6}\right)\left(27 \mathrm{~kJ} \mathrm{~mol}^{-1}\right){ }^{61}$ Such low adsorption heat denotes that LIFM-12 does not have a high affinity effect with $\mathrm{CO}_{2}$, thus regeneration procedure for industrial applications can be the energy conservation (please note that the adsorbed amounts of $\mathrm{CO}_{2}(298 \mathrm{~K})$ are lower than for CuBTTrimmen (4.2 mmol g ${ }^{-1}$ ), Bio-MOF-11 (4.1 mmol g $\left.{ }^{-1}\right),\{[\mathrm{CuL}]$. $\left.\mathrm{DMF} \cdot 2 \mathrm{H}_{2} \mathrm{O}\right\}_{n}\left(5.0 \mathrm{mmol} \mathrm{g}^{-1}\right)$ or $\left.\mathrm{Cu}(\mathrm{bpy}-1)_{2}\left(\mathrm{SiF}_{6}\right)\left(6.8 \mathrm{mmol} \mathrm{g}^{-1}\right)\right)$.

Gas selectivities of $\mathrm{CO}_{2} / \mathrm{N}_{2}, \mathrm{CO}_{2} / \mathrm{CH}_{4}$, and $\mathrm{CO}_{2} / \mathrm{CO}$ at $298 \mathrm{~K}$ based on ideal adsorption solution theory (IAST) ${ }^{62}$ were determined using experimental isotherms of $\mathrm{CO}_{2}, \mathrm{CH}_{4}, \mathrm{CO}$ and $\mathrm{N}_{2}$ (Fig. S19†). The values locate in the range of 23.2 to 26.1 for $\mathrm{CO}_{2} / \mathrm{N}_{2}$ (15: 85), 7.9 to 8.9 for $\mathrm{CO}_{2} / \mathrm{CH}_{4}(50: 50)$ and 1.0 to 1.1 for $\mathrm{CO}_{2} / \mathrm{CO}(50: 50)$ (Fig. 5a).
Table 2 Simulated solvent surface areas calculated by LIFM-12 and LIFM-12-HT

\begin{tabular}{llll}
\hline Model & Gas & $\begin{array}{l}\text { Solvent surface } \\
\left(\mathrm{m}^{2} \mathrm{~g}^{-1}\right)\end{array}$ & $\begin{array}{l}\text { Pore volume } \\
\left(\mathrm{cm}^{3} \mathrm{~g}^{-1}\right)\end{array}$ \\
\hline \multirow{2}{*}{ LIFM-12 } & $\mathrm{Ar}(87 \mathrm{~K})$ & 1342.7 & 0.47 \\
\multirow{2}{*}{ LIFM-12-HT } & $\mathrm{N}_{2}(77 \mathrm{~K})$ & 1253.7 & 0.463 \\
& $\mathrm{Ar}(87 \mathrm{~K})$ & 913.8 & 0.39 \\
& $\mathrm{~N}_{2}(77 \mathrm{~K})$ & 851.6 & 0.37 \\
\hline
\end{tabular}

All these values are close to that calculated by the Henry's law selectivity (Fig. S16 and Table S6†).

The adsorption of light alkanes and alkene of LIFM-12 clearly show that selectivities of $\mathrm{C}_{3} \mathrm{H}_{8} / \mathrm{CH}_{4}, \mathrm{C}_{3} \mathrm{H}_{6} / \mathrm{CH}_{4}, \mathrm{C}_{2} \mathrm{H}_{6} /$ $\mathrm{CH}_{4}$, and $\mathrm{C}_{3} \mathrm{H}_{8} / \mathrm{CH}_{4}$ are from 86.8 to $56.1,273.5$ to $188.3,27.5$ to 23.5 and 15.2 to 17.0 respectively (Fig. $5 \mathrm{~b}$ and $\mathrm{S} 17 \dagger$ ), which are also similar with the ones calculated by the Henry's law method (Table S7†). Both the adsorption amount and selectivity of LIFM-12 are higher than most of the MOFs reported for hydrocarbon separation, ${ }^{63}$ only lower than the MOF-74 series with UMCs, ${ }^{64}$ thus distinguishing LIFM-12 as an efficiency candidate of separation material of $\mathrm{C}_{2} / \mathrm{C}_{3}$ hydrocarbons from $\mathrm{CH}_{4}$ at the mild condition.

\section{Theoretical simulations of gas adsorption}

To understand the dynamics of LIFM-12 in the gas adsorption process, theoretical simulations using the Atom Volumes \& Surfaces tool of Material Studio have been performed on LIFM12-HT (OPM) and LIFM-12 (CPM). The simulation of $\mathrm{N}_{2}$ adsorption at $77 \mathrm{~K}$ show that BET surface area derived from CPM is $1253.7 \mathrm{~m}^{2} \mathrm{~g}^{-1}$, extremely close to the experimental value of $1221.1 \mathrm{~m}^{2} \mathrm{~g}^{-1}$ LIFM-12, which calculated by the pressure higher than $0.06 P / P_{0}$ (the last step), showing that the framework turns into CPM after filling $\mathrm{N}_{2}$ gas. The pore volume of the CPM calculated from $\mathrm{N}_{2}$ adsorption is estimated to be $0.51 \mathrm{~cm}^{3} \mathrm{~g}^{-1}$ at $P / P_{0}$ of 0.90 , which is larger than that of simulation value $(0.46$ $\mathrm{cm}^{3} \mathrm{~g}^{-1}$ at $P / P_{0}$ of 0.90$)$. The deviation may be contributed to the (a)

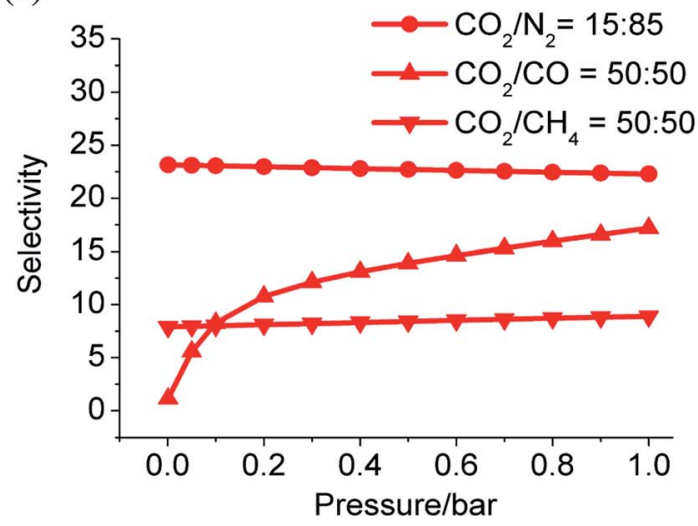

(b)

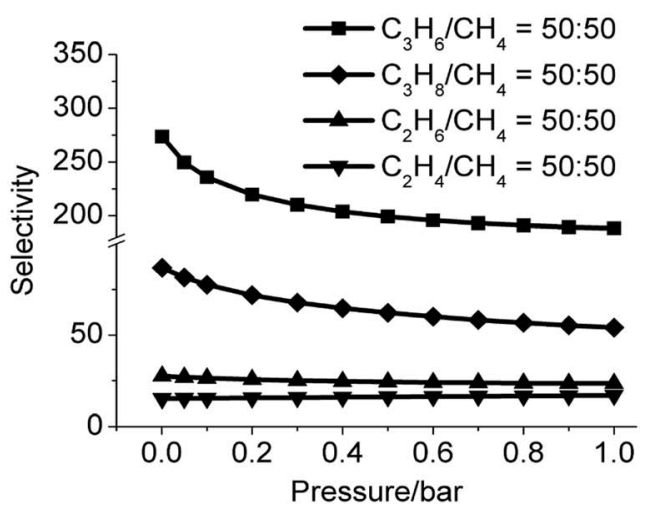

Fig. 5 Gas selectivity calculated by IAST, $\mathrm{CO}_{2}$ versus $\mathrm{N}_{2}, \mathrm{CO}, \mathrm{CH}_{4}$ (a) and $\mathrm{C}_{3} \mathrm{H}_{6}, \mathrm{C}_{3} \mathrm{H}_{8}, \mathrm{C}_{2} \mathrm{H}_{4}, \mathrm{C}_{2} \mathrm{H}_{6}$ versus $\mathrm{CH}_{4}$ (b) at $298 \mathrm{~K}$. 


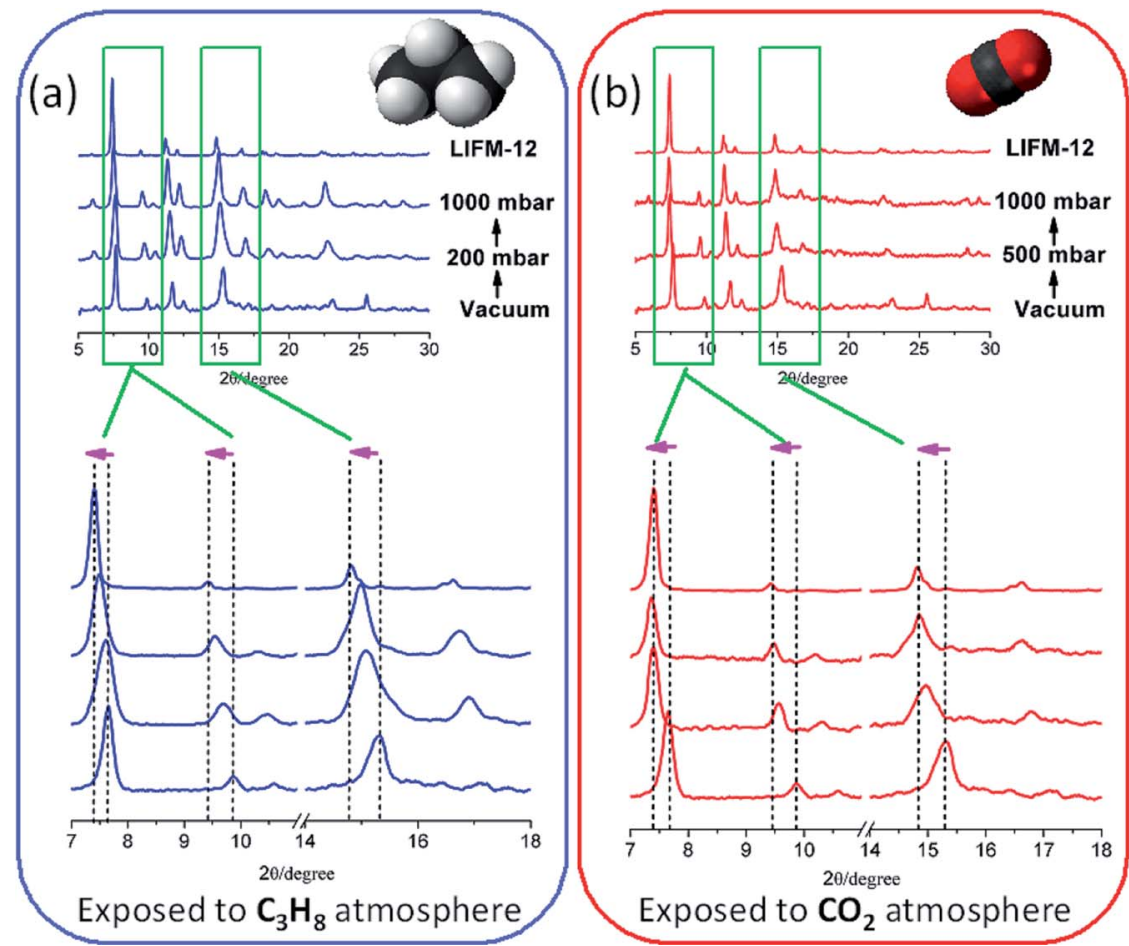

Fig. 6 (a) $\mathrm{C}_{3} \mathrm{H}_{8}$ and (b) $\mathrm{CO}_{2}$ absorption and induced in situ related pressure-dependent powder X-ray analysis.

unideal morphology of crystals, which creates a hierarchical porous macrostructure in the synthesis process (Table 2).

\section{Gas-induced in situ temperature-dependent PRXD}

The dynamic structural variation of the framework in response to gas adsorption through bond rotation within $\mathrm{NIA}^{2-}$ ligand is interesting. To get more structural insights for this process, herein we continually perform experimental gas-induced in situ pressure-dependent powder X-ray analysis to reveal the structural changes of LIFM-12 by removing and refilling guests under controllable pressure (Fig. 6).

The measurements started from OPM under vacuum for each gas, then fill $\mathrm{C}_{3} \mathrm{H}_{8}$ into the chamber. The PXRD patterns show an obvious offset in which the peaks moving towards to low $2 \theta$ angles (Scheme 2a). By continuing to fill the gas to the pressure at 1000 mbar, the patters shift to even lower $2 \theta$ angles, approaching the patterns of CPM. The dynamic change from OPM to CPM by filling the gas can also be proved by the $\mathrm{C}_{3} \mathrm{H}_{8}$ adsorption isotherms. As shown in Fig. 6a, in the initial stage, the framework is OPM, the adsorption is still at the first step, by continuously filling the gas, it is speculated that the pressure increase from 300 to $1000 \mathrm{mbar}$, the imine bonds gradually rotate during the whole $\mathrm{C}_{3} \mathrm{H}_{8}$ adsorption process, finally end as the CPM when the second step of the adsorption completes ( $P>2$ bar).

The PXRD response to $\mathrm{CO}_{2}$ filling is carried out in a similar method. By introducing $\mathrm{CO}_{2}$ into the sample chamber to a pressure of 500 mbar, PXRD patterns immediately move to lower $2 \theta$ angles, then the patterns keep the same and are similar to the CPM without changes after $\mathrm{CO}_{2}$ filling to the pressure at 1000 mbar. The phase change upon $\mathrm{CO}_{2}$ adsorption may stem from small critical molecular size for $\mathrm{CO}_{2}$, and/or kinetically favourable for $\mathrm{CO}_{2}$ diffusion in apertures at room temperature (Scheme 2b).

The above results indicate that the gas filling dependent PXRD analysis is reminiscent with the multistep absorption process involving sequential filling of the pores of different sizes. ${ }^{65}$ Comparing to the reported results, herein the "gateopen" effect is different from the so-called one of MIL-53, ${ }^{66}$ which excludes guest molecules in gate-closed structure. The multi-stepwise gas adsorption behaviour of LIFM-12 can be ascribed of the partly accessible void between the cavities A and $\mathrm{B}$, which can accommodate gases and exhibit framework flexibility, when the gate-open effect happens at specific pressure, the opened gate would kinetically facilitate adsorption process by relatively larger apertures, thus creating new steps in adsorption isotherms.

\section{Conclusions}

In summary, a flexible MOF LIFM-12 has been constructed, in which its flexibility can be triggered by the rotating of imine bond under the heating process and gas pressure variation. Gas adsorption results reveal that it possesses noticeable gas uptake and gas selectivity ability. In situ related pressuredependent PXRD verifies the stepwise adsorption starts from OPM, then develops to CPM by the increase of gas pressure variation. Our results provide a better understanding of the flexibility of MOFs upon the external stimulus and prop up the better design of responsive materials for particular applications in gas separation, molecular sensing, catalysis and et al. in the future. 


\section{Experimental section}

\section{Materials and physical measurements}

All chemicals were obtained from commercial sources and used without further purification. Solid-state IR spectra were recorded using Nicolet/Nexus-670 FT-IR spectrometer in the region of 4000-400 $\mathrm{cm}^{-1}$ using $\mathrm{KBr}$ pellets. Mass spectra (MS) were recorded on a JEOL accuTOF-CS, JMS-T100CS mass spectrometer. Elemental analyses were performed by PerkinElmer 240 elemental analyzer. Powder X-ray diffraction (XRD) measurements were performed on a Bruker D8 ADVANCE diffractometer at $40 \mathrm{kV}$ and $40 \mathrm{~mA}$ with a $\mathrm{Cu}$ target tube and a graphite monochromator. ${ }^{1} \mathrm{H}$ NMR spectra were measured with a Varian Mercury Plus $300 \mathrm{MHz}$ spectrometer. Thermogravimetric analysis (TGA) was performed on a NETZSCH TG209 system in nitrogen and under $1 \mathrm{~atm}$ of pressure at a heating rate of $10 \mathrm{~K} \mathrm{~min}^{-1}$.

Synthesis of $\mathrm{H}_{2}$ NIA. $\mathrm{H}_{2}$ NIA ligand was prepared with a modified method as previously reported. ${ }^{67} \mathrm{~A}$ mixture of nicotinic acid $(0.35 \mathrm{~mol})$ and freshly distilled thionyl chloride $(118 \mathrm{ml}, 1.6 \mathrm{~mol})$ were heated at $353 \mathrm{~K}$ for 6 hours. Then excess thionyl chloride was removed under flowing nitrogen gas. The resulting yellowish powder was used as prepared. Isonicotinoyl chloride hydrochloride in $20 \mathrm{ml}$ dimethylacetamide (DMAc) was added dropwise to a solution of 5-aminoisophthalic acid (0.30 $\mathrm{mol})$ and $N, N$-dimethylaminopyridine $(0.10 \mathrm{mmol})$ in $80 \mathrm{ml}$ DMAc at $273 \mathrm{~K}$ under nitrogen. Then the temperature was slowly raised to $313 \mathrm{~K}$ and kept at this temperature for $8 \mathrm{~h}$. The cooled mixture was poured into water, a precipitate formed and was filtered off, washed with hot water twice and dried under vacuum at $373 \mathrm{~K}$. The product was recrystallized twice in a mixture of dimethylformamide and water $(\mathrm{DMF}) / \mathrm{H}_{2} \mathrm{O}(3 / 2)$. Yield: $70 \% .{ }^{1} \mathrm{H}$ NMR [300 MHz, $\left(\mathrm{CD}_{3}\right)_{2} \mathrm{SO}$ ]: $10.76(\mathrm{~s}, 1 \mathrm{H}), 9.13$ $(\mathrm{d}, 1 \mathrm{H}), 8.76(\mathrm{dd}, 1 \mathrm{H}), 8.64(\mathrm{~d}, 2 \mathrm{H}), 8.32(\mathrm{tt}, 1 \mathrm{H}), 8.21(\mathrm{t}, 1 \mathrm{H}), 7.58$ (dd, 1H). MS [ESI ${ }^{-}$], $m / z$ calc.: 285.06, found: 285.31 .

Synthesis of LIFM-12. $\mathrm{H}_{2} \mathrm{NIA}(0.1 \mathrm{mmol}), \mathrm{Cu}\left(\mathrm{NO}_{3}\right)_{2} \cdot(0.1 \mathrm{mmol})$ were mixed and dispersed in DMF (4.0 ml) and methanol (4.0 $\mathrm{ml}$ ), then three drops of $\mathrm{HNO}_{3}$ was to this solution. The mixture was transferred into a $12 \mathrm{ml}$ autoclave, which was sealed and heated to $393 \mathrm{~K}$ for 4000 minutes. After cooling over 12 hours to room temperature, blue, slice microcrystalline product was obtained, then washed with DMF/methanol (1/1) and dried in air. Yield: 43\%. Elemental analysis (\% calc./found): C: 45.10/44.82, H: 4.18/4.72, N: 9.73/9.72. Selected IR: $\nu / \mathrm{cm}^{-1}: 3435$ (s), 1657 (s), 1639 (s), 1562 (s), 1477 (w), 1422 (s), 1375 (vs), 1293 (m), 1200 (w), $1111(\mathrm{~m}), 1052(\mathrm{~m}), 778(\mathrm{~m}), 730(\mathrm{~m}), 631(\mathrm{w}), 599(\mathrm{w}), 565(\mathrm{w})$.

\section{Temperature-dependent X-ray single crystal study}

A single crystal of LIFM-12 was carefully picked and coated in epoxy resin $\mathrm{AB}$ glue, attached to a glass silk inserted in a stainless steel stick, then quickly transferred to an Oxford Gemini S Ultra CCD diffractometer ( $\mathrm{Cu} \mathrm{K} \alpha$ radiation). Four sets of data were collected in sequence. (1) The single crystal exposed in a stream of nitrogen at $150 \mathrm{~K}$. (2) The single crystal was slowly heated to $435 \mathrm{~K}$ in nitrogen, kept still for 1.5 hours, and then the data was collected in nitrogen. (3) The single crystal was slowly cooled to $298 \mathrm{~K}$ in nitrogen, held for 1 hour more, and then the data was collected in nitrogen. (4) The nitrogen stream was shut off and the single crystal was exposed to air for 1 hour more, then the data was collected in the air at $298 \mathrm{~K}$. The structures were solved by direct methods and refined by full-matrix leastsquares based on $F^{2}$ using SHELXTL programme package. ${ }^{68}$ All nonhydrogen atoms were found from the Fourier difference maps and refined anisotropically. However, the hydrogen atoms of organic ligands were generated geometrically and refined using a riding model. The hydrogen atoms of water molecules were located using Fourier difference maps. CCDC reference number 1865055-1865058, contains the supplementary crystallographic data for this paper. $\dagger$

\section{In situ temperature-dependent PXRD of guest removal and inclusion}

A bulk sample of LIFM-12 was ground, flattened in a sample plate and conducted with a Bruker D8 Advance diffractometer which was equipped with a high temperature chamber. Four sets of data were collected. (1) The sample was heated up to 308 $\mathrm{K}$, kept for 1 hour, the PXRD pattern was collected in a nitrogen atmosphere. (2) The sample was continued to heat up to $435 \mathrm{~K}$ with a rate of $12 \mathrm{~K} \mathrm{~min}^{-1}$ in nitrogen, kept at $435 \mathrm{~K}$ for 1 hour and scanned in nitrogen. (3) The sample was later to cool to 298 $\mathrm{K}$ in natural rate in nitrogen, kept for 30 minutes, and scanned in nitrogen. (4) The samples were exposed to air, kept for 20 minutes, and then scanned in air.

\section{In situ temperature-dependent PXRD of $\mathrm{C}_{3} \mathrm{H}_{8}$ and $\mathrm{CO}_{2}$ filling}

The bulk sample was prior to removing the guest of solvent to afforded LIFM-12, then ground, flatten in a sample plate, and conducted with a Bruker D8 Advance diffractometer which is equipped with a high temperature chamber. The sample was heated to $435 \mathrm{~K}$ under vacuum and kept for 3 hours, following by slowly cooling to $298 \mathrm{~K}$. For $\mathrm{C}_{3} \mathrm{H}_{8}$ filling experiment, PXRD patterns of LIFM-12 were firstly collected under vacuum, then $\mathrm{C}_{3} \mathrm{H}_{8}$ was gradually filled into the chamber to the pressure of 300 mbar, keeping it for $30 \mathrm{~min}$, then PXRD patterns were collected; then increase the pressure to $1 \mathrm{bar}$, keeping it for 30 min and PXRD patterns were collected. For $\mathrm{CO}_{2}$ filling experiment, the PXRD patterns of LIFM-12 was firstly collected under vacuum, then $\mathrm{CO}_{2}$ was replenished to the pressure of 500 mbar, keeping it for $30 \mathrm{~min}$ and PXRD patterns were collected again; then increase the pressure to $1 \mathrm{bar}$, keeping it for $30 \mathrm{~min}$ and PXRD patterns were collected.

\section{Gas adsorption}

Gas adsorption isotherms for pressures in the range of 0-1.0 bar were obtained by a volumetric method using a Quantachrome autosorb-iQ2-MP gas adsorption analyzer. Argon adsorption isotherms were performed by the Belsorp-max gas adsorption analyzer. High pressure gas adsorption data was collected with the Belsorp-VC apparatus. The freshly prepared sample was transferred to a pre-dried and weighed analysis tube and evacuated at $433 \mathrm{~K}$ under a dynamic vacuum at $10^{-3}$ torr for 20 hours. Background adsorption values were deducted by blank measurement with an analysis tube. Gas adsorption measurements were performed using ultra-high purity $\mathrm{Ar}, \mathrm{N}_{2}, \mathrm{CO}, \mathrm{O}_{2}$, 
$\mathrm{He}, \mathrm{H}_{2}, \mathrm{CO}_{2}, \mathrm{CH}_{4}, \mathrm{C}_{2} \mathrm{H}_{6}, \mathrm{C}_{2} \mathrm{H}_{4}, \mathrm{C}_{3} \mathrm{H}_{8}$, and $\mathrm{C}_{3} \mathrm{H}_{6}$ gas. All solvents used as sources of vapor are the grade of HPLC.

\section{Calculations of adsorption isosteric heats}

The isosteric heats of $\mathrm{CO}_{2}$ adsorption for LIFM-12 were calculated base on the sorption data measured at 273, 298, $308 \mathrm{~K}$ by the virial fitting method, while that of $\mathrm{H}_{2}$ adsorption was calculated from the sorption data measured at 77, $87 \mathrm{~K}$. A virialtype expression (eqn (1)) which is composed of parameters $a_{i}$ and $b_{i}$ is used. In eqn (1), $P$ is the pressure in torr, $N$ is the adsorbed amount in mmol $\mathrm{g}^{-1}, T$ is the temperature in Kelvin, $a_{i}$ and $b_{i}$ are the virial coefficients which are independent of temperature, and $m$ and $n$ are the numbers of coefficients required to adequately describe the isotherms.

$$
\ln P=\ln N+\frac{1}{T} \sum_{i=0}^{m} a_{i} N^{i}+\sum_{i=0}^{n} b_{i} N^{i}
$$

The values of the virial coefficients $a_{0}$ through $a_{m}$ were then applied to calculate the isosteric heat of adsorption (eqn (2)). In eqn (2), $Q_{\text {st }}$ is the coverage-dependent isosteric heat of adsorption and $R$ is the universal gas constant.

$$
Q_{\mathrm{st}}=-R \sum_{i=0}^{m} a_{i} N^{i}
$$

\section{Calculations of adsorption selectivity}

Ideal adsorbed solution theory (IAST) developed by Myers and Prausnitz ${ }^{69}$ was used to calculate the selectivity of $\mathrm{CO}_{2} / \mathrm{N}_{2}$ (15:85), $\mathrm{CO}_{2} / \mathrm{CO}(50: 50)$ and $\mathrm{CO}_{2} / \mathrm{CH}_{4}$ (50:50) mixture compositions in LIFM-12 from their respective singlecomponent isotherms. The $\mathrm{CO}_{2}, \mathrm{~N}_{2}, \mathrm{CH}_{4}$ isotherms were fitted to the single-site Langmuir equation and the $\mathrm{CO}$ isotherms to the dual-sites Langmuir equation. Selectivity was then calculated according to eqn (3), where $x_{i}$ is the mole fraction of component $i$ in the adsorbed phase and $y_{i}$ is the mole fraction of component $i$ in the bulk.

$$
S=\frac{x_{i} y_{i}}{x_{j} y_{i}}
$$

Another virial fitting method based on the following equation:

$$
\ln N / P=A_{0}+A_{1} N+A_{2} N^{2}+A_{3} N^{3}+\cdots
$$

In eqn (4), $P$ is pressure, $N$ is amount adsorbed and $A_{0}, A_{1}$, etc. present virial coefficients. $A_{0}$ is related to adsorbate-adsorbent interactions, and $A_{1}$ describes adsorbate-adsorbate interactions. The Henry's law constant $\left(K_{\mathrm{H}}\right)$ is equal to $\exp \left(A_{0}\right)$.

The Henry's law selectivity for gas component $i$ over $j$ is calculated based on eqn (5):

$$
S_{i j}=K_{\mathrm{Hi}}+K_{\mathrm{H} j}
$$

\section{Simulation of surface area and pore size of LIFM-12}

Simulated surface area and pore size were calculated with Materials Studio (Version 4.0, Accelrys, San Diego, CA) using a nitrogen-sized probe molecule (diameter $3.64 \AA$ ) and Argonsized probe molecule (diameter $3.5 \AA$ ) with a grid interval of $0.40 \AA$ and grid solution of "Fine". The task of "Solvent surface" was chosen to calculate surface area and the "Connolly surface" was used for calculating pore size.

\section{Conflicts of interest}

There are no conflicts to declare.

\section{Acknowledgements}

This work was supported by NSFC (21821003, 21890380, 21890382, 21720102007, 21771197, 21605028), Local Innovative and Research Teams Project of Guangdong Pearl River Talents Program (2017BT01C161) and STP Project of Guangzhou (201607010378), Key Programs of Natural Science Funding Project of Liaoning Province (20180530085), Research Funding Project of Department of Education of Liaoning Province (JYTQN201924).

\section{References}

1 J.-R. Li, Y. Ma, M. C. McCarthy, J. Sculley, J. Yu, H.-K. Jeong, P. B. Balbuena and H.-C. Zhou, Coord. Chem. Rev., 2011, 255, 1791-1823.

2 J.-R. Li, J. Sculley and H.-C. Zhou, Chem. Rev., 2011, 112, 869932.

3 S. Qiu, M. Xue and G. Zhu, Chem. Soc. Rev., 2014, 43, 61166140.

4 M. K. Taylor, T. Runčevski, J. Oktawiec, J. E. Bachman, R. L. Siegelman, H. Jiang, J. A. Mason, J. D. Tarver and J. R. Long, J. Am. Chem. Soc., 2018, 140, 10324-10331.

5 K. Sumida, D. L. Rogow, J. A. Mason, T. M. McDonald, E. D. Bloch, Z. R. Herm, T.-H. Bae and J. R. Long, Chem. Rev., 2011, 112, 724-781.

6 X. Duan, J. Yu, J. Cai, Y. He, C. Wu, W. Zhou, T. Yildirim, Z. Zhang, S. Xiang, M. O'Keeffe, B. Chen and G. Qian, Chem. Commun., 2013, 49, 2043-2045.

7 F. Moreau, I. da Silva, N. H. Al Smail, T. L. Easun, M. Savage, H. G. W. Godfrey, S. F. Parker, P. Manuel, S. Yang and M. Schröder, Nat. Commun., 2017, 8, 14085.

8 T. Tian, Z. Zeng, D. Vulpe, M. E. Casco, G. Divitini, P. A. Midgley, J. Silvestre-Albero, J.-C. Tan, P. Z. Moghadam and D. Fairen-Jimenez, Nat. Mater., 2017, 17, 174.

9 D. N. Dybtsev, A. L. Nuzhdin, H. Chun, K. P. Bryliakov, E. P. Talsi, V. P. Fedin and K. Kim, Angew. Chem., Int. Ed., 2006, 45, 916-920.

10 C. Wang, J.-L. Wang and W. Lin, J. Am. Chem. Soc., 2012, 134, 19895-19908.

11 A. Dhakshinamoorthy, M. Opanasenko, J. Čejka and H. Garcia, Catal. Sci. Technol., 2013, 3, 2509-2540. 
12 J. Liu, L. Chen, H. Cui, J. Zhang, L. Zhang and C.-Y. Su, Chem. Soc. Rev., 2014, 43, 6011-6061.

13 J. W. Maina, C. Pozo-Gonzalo, L. Kong, J. Schütz, M. Hill and L. F. Dumée, Mater. Horiz., 2017, 4, 345-361.

14 R. Kitaura, K. Seki, G. Akiyama and S. Kitagawa, Angew. Chem., Int. Ed., 2003, 42, 428-431.

15 N. Nijem, H. Wu, P. Canepa, A. Marti, K. J. Balkus, T. Thonhauser, J. Li and Y. J. Chabal, J. Am. Chem. Soc., 2012, 134, 15201-15204.

16 Q.-Y. Yang, P. Lama, S. Sen, M. Lusi, K.-J. Chen, W.-Y. Gao, M. Shivanna, T. Pham, N. Hosono, S. Kusaka, J. J. Perry IV, S. Ma, B. Space, L. J. Barbour, S. Kitagawa and M. J. Zaworotko, Angew. Chem., Int. Ed., 2018, 57, 5684-5689.

17 K. Barthelet, J. Marrot, D. Riou and G. Férey, Angew. Chem., Int. Ed., 2002, 41, 281-284.

18 L. Chen, J. P. S. Mowat, D. Fairen-Jimenez, C. A. Morrison, S. P. Thompson, P. A. Wright and T. Düren, J. Am. Chem. Soc., 2013, 135, 15763-15773.

19 M. K. Taylor, T. Runčevski, J. Oktawiec, M. I. Gonzalez, R. L. Siegelman, J. A. Mason, J. Ye, C. M. Brown and J. R. Long, J. Am. Chem. Soc., 2016, 138, 15019-15026.

20 C.-X. Chen, Z. Wei, J.-J. Jiang, Y.-Z. Fan, S.-P. Zheng, C.-C. Cao, Y.-H. Li, D. Fenske and C.-Y. Su, Angew. Chem., Int. Ed., 2016, 55, 9932-9936.

21 C. Gücüyener, J. van den Bergh, J. Gascon and F. Kapteijn, J. Am. Chem. Soc., 2010, 132, 17704-17706.

22 L. Bolinois, T. Kundu, X. Wang, Y. Wang, Z. Hu, K. Koh and D. Zhao, Chem. Commun., 2017, 53, 8118-8121.

23 G. J. Halder, C. J. Kepert, B. Moubaraki, K. S. Murray and J. D. Cashion, Science, 2002, 298, 1762.

24 B. Li and B. Chen, Sci. China: Chem., 2016, 59, 965-969.

25 D. Bradshaw, J. E. Warren and M. J. Rosseinsky, Science, 2007, 315, 977.

26 R. Matsuda, R. Kitaura, S. Kitagawa, Y. Kubota, T. C. Kobayashi, S. Horike and M. Takata, J. Am. Chem. Soc., 2004, 126, 14063-14070.

27 Y. Zhang, X. Zhang, J. Lyu, K.-i. Otake, X. Wang, L. R. Redfern, C. D. Malliakas, Z. Li, T. Islamoglu, B. Wang and O. K. Farha, J. Am. Chem. Soc., 2018, 140, 11179-11183.

28 S. Horike, R. Matsuda, D. Tanaka, S. Matsubara, M. Mizuno, K. Endo and S. Kitagawa, Angew. Chem., Int. Ed., 2006, 45, 7226-7230.

29 E. Y. Lee, S. Y. Jang and M. P. Suh, J. Am. Chem. Soc., 2005, 127, 6374-6381.

30 J. Seo, R. Matsuda, H. Sakamoto, C. Bonneau and S. Kitagawa, J. Am. Chem. Soc., 2009, 131, 12792-12800.

31 A. Schneemann, V. Bon, I. Schwedler, I. Senkovska, S. Kaskel and R. A. Fischer, Chem. Soc. Rev., 2014, 43, 6062-6096.

32 Z.-J. Lin, J. Lü, M. Hong and R. Cao, Chem. Soc. Rev., 2014, 43, 5867-5895.

33 S. M. J. Rogge, M. Waroquier and V. Van Speybroeck, Acc. Chem. Res., 2018, 51, 138-148.

34 J. Zhang, L. Wojtas, R. W. Larsen, M. Eddaoudi and M. J. Zaworotko, J. Am. Chem. Soc., 2009, 131, 17040-17041.

35 O. Shekhah, H. Wang, M. Paradinas, C. Ocal, B. Schüpbach, A. Terfort, D. Zacher, R. A. Fischer and C. Wöll, Nat. Mater., $2009,8,481$.
36 O. K. Farha, C. D. Malliakas, M. G. Kanatzidis and J. T. Hupp, J. Am. Chem. Soc., 2010, 132, 950-952.

37 R. Yang, L. Li, Y. Xiong, J.-R. Li, H.-C. Zhou and C.-Y. Su, Chem.-Asian J., 2010, 5, 2358-2368.

38 C.-X. Chen, Q.-F. Qiu, C.-C. Cao, M. Pan, H.-P. Wang, J.-J. Jiang, Z.-W. Wei, K. Zhu, G. Li and C.-Y. Su, Chem. Commun., 2017, 53, 11403-11406.

39 C.-X. Chen, Z.-W. Wei, J.-J. Jiang, S.-P. Zheng, H.-P. Wang, Q.-F. Qiu, C.-C. Cao, D. Fenske and C.-Y. Su, J. Am. Chem. Soc., 2017, 139, 6034-6037.

40 Y. Chen, J. Zhou, F. Vajda, P. Maguire, R. O'Connell, W. Schmitt, Y. Li, Z. Yan, Y. Zhang and H. Zhang, Cryst. Growth Des., 2017, 17, 1568-1573.

41 C.-X. Chen, S.-P. Zheng, Z.-W. Wei, C.-C. Cao, H.-P. Wang, D. Wang, J.-J. Jiang, D. Fenske and C.-Y. Su, Chem.-Eur. J., 2017, 23, 4060-4064.

42 J.-P. Zhang and X.-M. Chen, J. Am. Chem. Soc., 2008, 130, 6010-6017.

43 Y. Liu, J. F. Eubank, A. J. Cairns, J. Eckert, V. C. Kravtsov, R. Luebke and M. Eddaoudi, Angew. Chem., Int. Ed., 2007, 46, 3278-3283.

44 H. Kim, D. G. Samsonenko, M. Yoon, J. W. Yoon, Y. K. Hwang, J.-S. Chang and K. Kim, Chem. Commun., 2008, 4697-4699.

45 Y. Yue, J. A. Rabone, H. Liu, S. M. Mahurin, M.-R. Li, H. Wang, Z. Lu, B. Chen, J. Wang, Y. Fang and S. Dai, J. Phys. Chem. C, 2015, 119, 9442-9449.

46 D. Zhao, X. Rao, J. Yu, Y. Cui, Y. Yang and G. Qian, Inorg. Chem., 2015, 54, 11193-11199.

47 Y. Xiong, Y.-Z. Fan, R. Yang, S. Chen, M. Pan, J.-J. Jiang and C.-Y. Su, Chem. Commun., 2014, 50, 14631-14634.

48 Y. Xiong, Y.-Z. Fan, D. Damasceno Borges, C.-X. Chen, Z.-W. Wei, H.-P. Wang, M. Pan, J.-J. Jiang, G. Maurin and C.-Y. Su, Chem.-Eur. J., 2016, 22, 16147-16156.

49 S. Wang, Z.-W. Wei, J. Zhang, L. Jiang, D. Liu, J.-J. Jiang, R. Si and C.-Y. Su, IUCrJ, 2019, 6, 85-95.

50 Z. Chen, K. Adil, Ł. J. Weseliński, Y. Belmabkhout and M. Eddaoudi, J. Mater. Chem. A, 2015, 3, 6276-6281.

51 V. Blatov, TOPOS, IUCr Compcomm, 2006.

52 V. A. Blatov and D. M. Proserpio, Acta Crystallogr., Sect. A: Found. Crystallogr., 2009, 65, 202-212.

53 A. Spek, J. Appl. Crystallogr., 2003, 36, 7-13.

54 Q. Wei, D. Yang, T. E. Larson, T. L. Kinnibrugh, R. Zou, N. J. Henson, T. Timofeeva, H. Xu, Y. Zhao and B. R. Mattes, J. Mater. Chem., 2012, 22, 10166-10171.

55 J. L. C. Rowsell and O. M. Yaghi, J. Am. Chem. Soc., 2006, 128, 1304-1315.

56 L. Czepirski and J. JagieŁŁo, Chem. Eng. Sci., 1989, 44, 797801.

57 J. Jagiełło, T. J. Bandosz and J. A. Schwarz, Langmuir, 1996, 12, 2837-2842.

58 T. M. McDonald, D. M. D'Alessandro, R. Krishna and J. R. Long, Chem. Sci., 2011, 2, 2022-2028.

59 J. An, S. J. Geib and N. L. Rosi, J. Am. Chem. Soc., 2010, 132, 38-39.

60 L. Wen, W. Shi, X. Chen, H. Li and P. Cheng, Eur. J. Inorg. Chem., 2012, 2012, 3562-3568. 
61 S. D. Burd, S. Ma, J. A. Perman, B. J. Sikora, R. Q. Snurr, P. K. Thallapally, J. Tian, L. Wojtas and M. J. Zaworotko, J. Am. Chem. Soc., 2012, 134, 3663-3666.

62 A. L. Myers and J. M. Prausnitz, AIChE J., 1965, 11, 121-127.

63 H. Wu, Q. Gong, D. H. Olson and J. Li, Chem. Rev., 2012, 112, 836-868.

64 E. D. Bloch, W. L. Queen, R. Krishna, J. M. Zadrozny, C. M. Brown and J. R. Long, Science, 2012, 335, 1606-1610.

65 W. Zhuang, S. Ma, X.-S. Wang, D. Yuan, J.-R. Li, D. Zhao and H.-C. Zhou, Chem. Commun., 2010, 46, 5223-5225.
66 F. Millange, C. Serre and G. Férey, Chem. Commun., 2002, 822-823, DOI: 10.1039/B201381A.

67 J. J. Ferreiro, J. G. de la Campa, A. E. Lozano and J. de Abajo, J. Polym. Sci., Part A: Polym. Chem., 2005, 43, 5300-5311.

68 G. Sheldrick, Acta Crystallogr., Sect. A: Found. Crystallogr., 2008, 64, 112-122.

69 C. Serre, F. Millange, C. Thouvenot, M. Noguès, G. Marsolier, D. Louër and G. Férey, J. Am. Chem. Soc., 2002, 124, 1351913526. 